
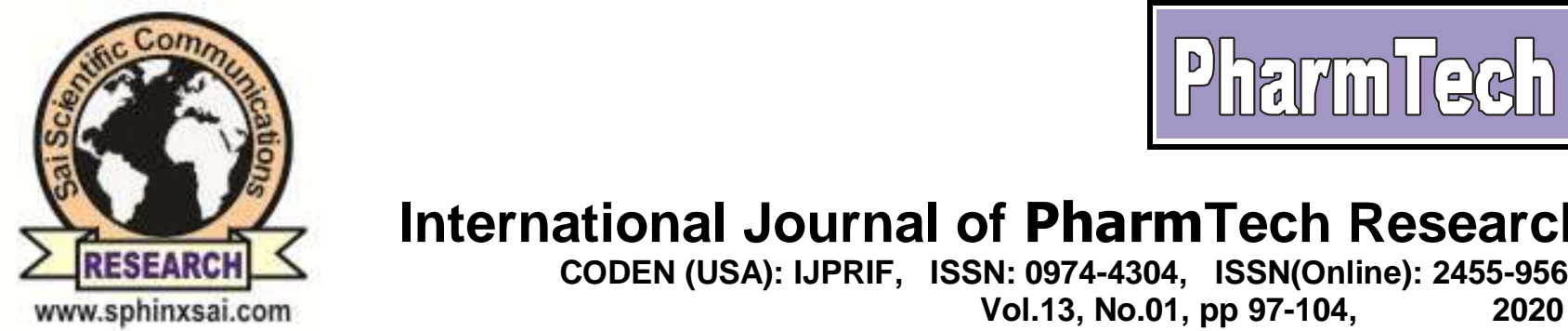

International Journal of PharmTech Research CODEN (USA): IJPRIF, ISSN: 0974-4304, ISSN(Online): 2455-9563

Vol.13, No.01, pp 97-104,

2020

\title{
Trauma Analysis Related Injury Severity Score (Triss) in Predicting the Prognosis of Politrauma Patients in Adam Malik General Hospital
}

\author{
Rahmad Gunawan $^{1 *}$, Heru Rahmadhany ${ }^{2}$, Iman Dwi Winanto ${ }^{3}$ \\ ${ }^{1}$ Resident of Orthopaedic and Traumatology, Faculty of Medicine Universitas \\ Sumatera Utara/ Haji Adam Malik Hospital-Medan, Indonesia \\ ${ }^{1}$ Consultant of Orthopaedic and Traumatology, Spine Division, Faculty of Medicine \\ Universitas Sumatera Utara/ Haji Adam Malik Hospital-Medan, Indonesia \\ ${ }^{3}$ Consultant of Orthopaedic and Traumatology, Pediatric Division, Faculty of Medicine \\ Universitas Sumatera Utara/ Haji Adam Malik Hospital-Medan, Indonesia
}

\begin{abstract}
Objective : The purposeofthis study wastoanalyzetheabilityof TRISS in predictingthe prognosis ofpolytraumapatients in the Haji Adam Malik General Hospital Medan, January 2016 toDecember 2018.

Material and Method : This type of research is an analytic study with cross sectional design, which is a study by measuring independent variables and dependent variables at the same time, which aims to analyze the ability of TRISS in predicting the prognosis of patients in Haji Adam Malik General Hospital Medan January 2016 to December 2018.

Results : From January 2016 - December 2018, a total 175 polytrauma patients which mostly was adult patient (>18 y.o) observed. Based on sex, referral status and diagnosis, patients with polytrauma dominated in patients with male sex(143 patients), referred patient (68patients) and diagnosed with head injury (29 patients).

Conclusion : There is an influence between TRISS Score on the prognosis of polytrauma patients.
\end{abstract}

Keywords : TIRSS, polytrauma, trauma, trauma prognosis.

Introduction:

Trauma is one of the main health problems and is a major cause of death in adolescents and young adults. In Indonesia, injury is the number four cause of death, whereas in the age group 15-25 years trauma is the main cause of death. Traffic accidents (KLL) are the most common cause of injury worldwide. Injury due to KLL is a major cause of death and disability in general, especially in developing countries. Based on WHO data in 2000, there were 5.8 million fatal injuries and ranked 7th as the cause of death worldwide. During 2002 the KLL was ranked 11th as a cause of death worldwide and is expected to continue to increase, even in 2020 it is predicted to rank third as the cause of death worldwide as the automotive industry worldwide increases (Levin et al. 2007).

Rahmad Gunawan et al /International Journal of PharmTech Research, 2020,13(1): 97-104.

DOI= http://dx.doi.org/10.20902/IJPTR.2019.130111 
Given the high incidence of trauma, a scoring or scoring system is needed that can change the quality of trauma in the form of scores or numbers (Levin et al, 2007). This scoring system feels necessary because it can predict mortality, compare therapeutic methods, is a pre and inter hospital triage tool, assesses quality improvement and prevention programs, and is a tool for trauma research (Chawda et al, 2004).

According to Becher et al (2013) the scoring system in determining the severity of trauma varies from the beginning of its manufacture. Some scoring systems available include Revised Trauma Score (RTS), Injury Severity Score (ISS), and Trauma Related Injury Severity Score (TRISS). This scoring system was chosen because it is often used in trauma research articles.

RTS assesses the human physiological system as a whole, is the result of perfecting the GCS instrument (Glasgow Coma Scale) to assess the initial condition of head trauma patients. The RTS assessment is carried out immediately after the patient is injured, generally just before entering the hospital or while in the emergency department (Kondo et al, 2011).

ISS is an extensive injury assessment system used to assess injuries based on anatomic injury assessment, which can provide overall scores for patients with multiple injuries. The higher the score, the greater the severity of the patient and its consequences, and the mortality will be higher (Eid and Abuzidan, 2014).

TRISS is a more comprehensive method by combining anatomic and physiological measurements of the severity of the wound (ISS and RTS), and also the patient's age in order to estimate the prognosis of a trauma (Byod et al, 1987). By recognizing the difference between blunt and sharp wounds, the researchers developed different methods for each mechanism of trauma. TRISS can be used for adult patients and children over the age of 12 years (Brilez et al, 2010).

Previous research on the TRISS Score was investigated by BambangGunawan, et al (2017) in polytrauma patients in the Emergency Department of the National Center General Hospital Dr. CiptoMangunkusumo (RSUPNCM). In his research, it was examined and processed statistically four variables namely TRISS Score, Response Time, Gender, Reference Status, and it was found that the TRISS Score was very good in predicting the prognosis of polytrauma patients with a value of $89.9 \%$.

It is very important to analyze the scoring system that affects the prediction of patient prognosis in cases, especially in H. Adam Malik General Hospital, as the only class A trauma referral hospital in North Sumatra Province. In H. Adam Malik General Hospital there is no research on TRISS Score analysis to be able to predict the patient's prognosis so it is necessary to conduct this study.

\section{Method:}

This type of research is an analytic study with cross sectional design which aims to analyze the ability of TRISS (Trauma Related Injury Severity Score) in predicting the prognosis of patients in Haji Adam Malik General Hospital Medan January 2016 to December 2018. The samples was collected from medical records (gender, referrral status, diagnosis and response time). The gathered data then analyzed with univariate, bivariate and multivariate analysis for correlation for prognosis.

In this study no intervention was made in the study sample because the data used in this study came from medical records. Before conducting research, the protocol will be asked for Ethical Clearance from the Haji Adam Malik Hospital Ethics Committee.

\section{Result:}

Characteristics of subjects in this study in patients with polytrauma based on age, sex, response time, referral status, TRISS Score and patient prognosis and can be seen in Table 1. 
Table 1.Distribution of Research Subjects

\begin{tabular}{|l|l|l|}
\hline Characteristic & n & \% \\
\hline Age & & \\
\hline$<18$ year & 37 & 21,1 \\
\hline$>18$ year & 138 & 78,9 \\
\hline Gender & & \\
\hline Male & 143 & 81,7 \\
\hline Female & 32 & 18,3 \\
\hline Respons time & & \\
\hline$<1 \mathrm{~h}$ & 119 & 68,0 \\
\hline $1-6 \mathrm{~h}$ & 45 & 25,7 \\
$7-24 \mathrm{~h}$ & 11 & 6,3 \\
$>24 \mathrm{~h}$ & 0 & 0 \\
\hline Referal Status & & \\
Refer & 107 & 61,1 \\
Not refer & 68 & 38,9 \\
\hline TRISS Score & & \\
Good probability of survival & 152 & 86,9 \\
Poor probability of survival & 23 & 13,1 \\
\hline Prognosis & & \\
Life & 160 & 91,4 \\
Death & 15 & 8,6 \\
\hline Total & $\mathbf{1 7 5}$ & $\mathbf{1 0 0}$ \\
\hline
\end{tabular}

From tabel 1, it coul be seen that from 175 polytrauma patients in the age group < 18 years, 37 patients $(21.1 \%)$ and 138 patients in the age group $>18$ years $(18.9 \%)$ patients, meaning that polytrauma patients mostlyoccured in adult patients.Based on sex, patients with polytrauma more in patients with male sex as many as 143 patients $(81.7 \%)$ while in female patients as many as 32 patients $(18.3 \%)$. Based on the response time of patients at most in the category $<1$ hour as many as 119 patients $(68 \%)$ followed by the response time category 1-6 hours that is as many as 45 patients $(25.7 \%)$, while for the category 7-24 hours only 11 patients $(6,3 \%)$.

Then based on referral status, most patients were referred, namely 107 patients $(61.1 \%)$, while patients who were not referred were 68 patients (38.9). Then from TRISS Score the most patients in the category of good probability of survival that is as many as 152 patients $(86.9 \%)$, while the probability of poor survival is only 23 patients (13.1\%). For the prognosis of the most patients in the group of living patients, 160 patients (91.4\%), while only 15 patients died $(8.6 \%)$.

Table 2.Distribution Based on Diagnosis

\begin{tabular}{|l|l|l|}
\hline Diangosis & n & \% \\
\hline Head Injury & 29 & 17.4 \\
\hline Lacerated Wound & 23 & 13.8 \\
\hline Closed Femur Fracture & 20 & 12.0 \\
\hline Mandible Fracture & 19 & 11.4 \\
\hline Blunt Thoracal Injury & 18 & 10.8 \\
\hline Scald Burn Injury & 17 & 10.2 \\
\hline Hematothorax & 12 & 7.2 \\
\hline Blunt Abdominal Injury & 10 & 6.0 \\
\hline Closed Clavicle Fracture & 10 & 6.0 \\
\hline Closed Humerus Fracture & 9 & 5.4 \\
\hline
\end{tabular}


From table 2, this study found that the majority of patients with a diagnosis of Head Injury were 29 people (17.4\%). Then patients with a diagnosis of Closed Femur Fracture are as many as 20 people (12\%). The patients with the least diagnosis were in the case of Closed Humerus Fracture, 9 patients (5.4\%).

Bivariate analysis was performed to determine the relationship of each independent variable, namely gender, referral status, response time and TRISS Score with the dependent variable, namely the patient's prognosis presented in the form of a cross table. Data processing in bivariate analysis using Chi-Square test.

Table 3.Bivariate analysis between independent variables and prognosis

\begin{tabular}{|c|c|c|c|c|c|c|c|}
\hline \multirow{3}{*}{$\begin{array}{l}\text { Independent } \\
\text { variable }\end{array}$} & \multicolumn{4}{|c|}{ Patient Prognosis } & \multirow{2}{*}{\multicolumn{2}{|c|}{ Sum }} & \multirow{3}{*}{$p$. } \\
\hline & \multicolumn{2}{|c|}{ Life } & \multicolumn{2}{|c|}{ Death } & & & \\
\hline & n & $\%$ & $\mathbf{n}$ & $\%$ & $\mathbf{n}$ & $\%$ & \\
\hline $\begin{array}{l}\text { Gender } \\
\text { Male }\end{array}$ & 130 & 90,9 & 13 & 91,9 & 143 & 100 & 0,865 \\
\hline Female & 30 & 93,8 & 2 & 6,2 & 32 & 100 & \\
\hline $\begin{array}{l}\text { Referal status } \\
\text { Refer }\end{array}$ & 96 & 89,7 & 11 & 10,3 & 107 & 100 & 0,462 \\
\hline Not refer & 64 & 94,1 & 4 & 5,9 & 68 & 100 & \\
\hline $\begin{array}{l}\text { Respons Time } \\
<1 \mathrm{~h}\end{array}$ & 110 & 92,4 & 9 & 7,6 & 119 & 100 & \\
\hline $\begin{array}{l}1-6 h \\
7-24 h\end{array}$ & $\begin{array}{l}39 \\
11\end{array}$ & $\begin{array}{l}86,7 \\
100\end{array}$ & $\begin{array}{l}6 \\
0\end{array}$ & $\begin{array}{l}13,3 \\
0\end{array}$ & $\begin{array}{l}45 \\
11\end{array}$ & $\begin{array}{l}100 \\
100\end{array}$ & 0,288 \\
\hline $\begin{array}{l}\text { Triss Score } \\
\text { Good probability }\end{array}$ & 151 & 99,3 & 1 & 0,7 & 152 & 100 & $<0,001$ \\
\hline Poor probability & 9 & 39,1 & 14 & 61,9 & 23 & 100 & \\
\hline Total & 160 & 91,4 & 15 & 8,6 & 175 & 100 & \\
\hline
\end{tabular}

In table 3 above we get the results of the analysis using chi square to identify the relationship between the sex of the patient and the prognosis of polytrauma patients showing that the results of the analysis test found that the value of $p=0.865>0.05$ which means there is no significant relationship between the sexes with prognosis of polytrauma patients.

Then the relationship between the referral status of patients with the prognosis of polytrauma patients showed that the results of the analysis test found that the value of $p=0.462>0.05$ which means there is no significant relationship between the referral status with the prognosis of polytrauma patients.

The response time variable also did not show a significant relationship with the prognosis of polytrauma patients because the value of $p=0.462>0.05$. The results of the analysis using chi square to identify the relationship between TRISS Score of patients with the prognosis of polytrauma patients showed that the results of the analysis test showed that the value of $p<0.001<0.05$, which means there is a significant relationship between TRISS Score with the prognosis of polytrauma patients.

Multivariate analysis is used to explain the independent variables that most influence the dependent variable. In this study, the multivariate analysis used was a logistic regression test. The stages carried out in multivariate analysis are as follows.

Selection of variable candidates to be multivariate tested by entering independent variables include gender, reference status, response time and TRISS Score on the dependent variable, namely the Prognosis of Politrauma Patients. Variables that have a $\mathrm{p}$ value $<0.25$ will be included in the multivariate analysis. From the results of the candidate test, it was found that the independent variables, among others, Gender and TRISS Score had a value of $\mathrm{p}<0.25$. The selection results of these variables can be seen in the following table: 
Table 4.Independent Variable Candidate Test Results

\begin{tabular}{|l|l|}
\hline Variable & Sig value $(\boldsymbol{p})$ \\
\hline Gender & 0,606 \\
Referal status & 0,317 \\
Respons Time & 0,908 \\
Triss Score & $<0,001$ \\
\hline
\end{tabular}

In the final multivariate modeling with logistic regression test shows that the Triss Score variable has a $\mathrm{p}$ value of less than 0.05 ( $\mathrm{p}$ value $<0.05$ ), so that the variable is the final multivariate modeling after a logistic regression test of two modeling stages. Multivariate analysis results can be concluded that the TRISS Score variable has a strong influence on the prognosis of polytrauma patients. it means TRISS Score is the most dominant variable influencing the prognosis of Politrauma patients. The results of the analysis can be seen in the following table.

Table 5.Results of Multivariate Logistic Regression Analysis

\begin{tabular}{|c|c|c|c|c|c|c|c|}
\hline & & B & S.E. & Wald & df & Sig. & $\operatorname{Exp}(B)$ \\
\hline \multirow{3}{*}{ Step $1^{\mathrm{a}}$} & TrissScore & 5.756 & 1.126 & 26.114 & 1 & .000 & 316.107 \\
\hline & Gender & -1.610 & 1.001 & 2.586 & 1 & .108 & .200 \\
\hline & Constant & -9.015 & 2.211 & 16.622 & 1 & .000 & .000 \\
\hline \multirow{2}{*}{ Step $2^{\mathrm{a}}$} & TrissScore & 5.459 & 1.090 & 25.061 & 1 & .000 & 234.889 \\
\hline & Constant & -10.476 & 2.052 & 26.076 & 1 & .000 & .000 \\
\hline
\end{tabular}

The $p$ value of the effect of the TRISS Score on the prognosis of polytrauma patients is $p<0.0001$. This shows that there is a significant influence between TRISS Score and the prognosis of polytrauma patients.

Table 6.AUC Value (Area Under the Curve)

\begin{tabular}{|c|c|c|c|c|}
\hline \multirow{2}{*}{ Area } & \multirow{2}{*}{ Std. Error ${ }^{\mathrm{a}}$} & \multirow{2}{*}{ Asymptotic Sig. } & \multicolumn{2}{|c|}{ Asymptotic 95\% Confidence Interval } \\
\hline & & & Lower Bound & Upper Bound \\
\hline 939 & .039 & .000 & .863 & 1.000 \\
\hline
\end{tabular}

In table 4.6.above it was found that the Triss score has a perfect AUC score of 0.939 or $93.9 \%$ which means the TRISS Score is very strong in predicting the prognosis of polytrauma patients.

\section{Discussion:}

The results of this study are consistent with the theory that the TRISS Score is an assessment of trauma scores with the highest sensitivity and specificity compared to ISS, SKG, and RTS. (Al Eassa, 2013; Salim, 2015). This study is also in line with research conducted by Bambang Gunawan, et al (2017) in polytrauma patients in the Emergency Department (IGD) of the National Center General Hospital Dr. CiptoMangunkusumo (RSUPNCM). In his research between the TRISS Score variable with the prognosis of polytrauma patients have a significant correlation with the $\mathrm{p}$ value of the TRISS Score variable is $<0.001$.

Then this study is also in line with research conducted by Nangarwal et al, (2017). From the results of statistical analysis using the chi square test on the TRISS Score variable on the patient's prognosis shows a $p$ value $<0.001$ which means there is a significant relationship to the prognosis of trauma patients.

This study is also in line with research conducted by Bambang Gunawan, et al (2017) in polytrauma patients in the Emergency Department (IGD) of the National Center General Hospital Dr. Cipto Mangunkusumo (RSUPNCM). In his research it was found that TRISS Score has a high AUC value of $89.9 \%$. 
A high TRISS score represents a higher life expectancy, with a sensitivity of $94 \%$ and specificity reaching $100 \%$. This is consistent with the osaka study comparing the RTS, ISS, and TRISS Scoring systems showing that the TRISS Score has the highest sensitivity, specificity, and accuracy (95, 96, 95\%). (Al Eassa, 2013. The results of the curve can be seen in the following figure.

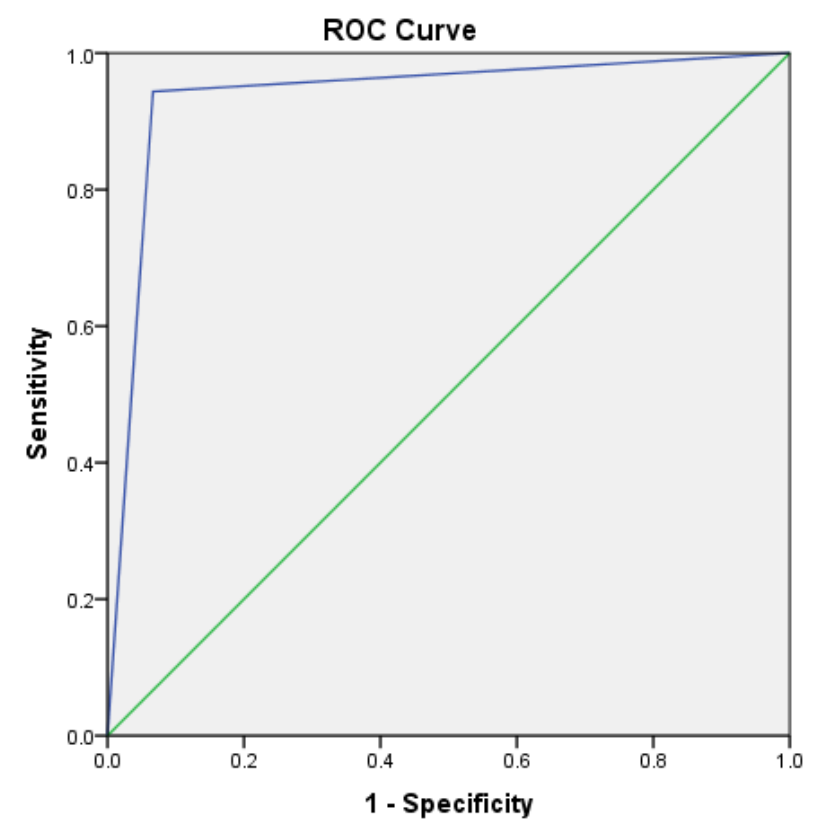

Diagonal segments are produced by ties.

\section{Figure 1.TRISS Score Receiver Operating Characteristic Curve}

\section{Conclusion:}

From this study it can be concluded that there is an influence between TRISS Score on the prognosis of polytrauma patients, no effect between response time on the prognosis of polytrauma patients, no influence between sex on the prognosis of polytrauma patients., no effect of referral status on the prognosis of polytrauma patients.A high TRISS score represents a higher life expectancy, with a sensitivity of $94 \%$ and specificity reaching $100 \%$.

\section{References:}

1. Levin D, Bachis C, Acosta JA, Jacoby IJ. Trauma scoring and triage. Trsums, Emergency Resuscitation, Perioperative Anesthesia, Surgical Management, Informa Health care. 2007;1:59-81.

2. Chawda MN, Hildebrand F, Pape HC, Giannoudis PV. Predicting outcome after multiple trauma: Which scoring system? Injury. 2004;35(4):347-58.

3. Becher RD, Meredith JW, Kilgo PD. Injury Severity Scoring and outcome research. Trauma (7th ed). McGrawHill, 2013; p. 77-90.

4. Kondo Y, Abe T, Kohshi K, Tokuda Y, Cook EF, Kukita I. Revised trauma scoring system to predict in-hospital mortality in the Emergency Department: Glasgow Coma Scale, Age, and Systolic Blood Pressure Score. Critical Care. 2011;15(R):191.

5. Eid HO, Abuzidan FM. New Injury Severity Score is a better predictor of mortality for blunt trauma patients than the Injury Severity Score. World Journal of Surgery. 2015;39:165-71.

6. Boyd CR, Tolson MA, Copes WS. Evaluating trauma care: The TRISS method. The Journal of Trauma. 1987;27(4):370-8.

7. Brilej D, Vlaovic M, Komadina R. Improved prediction from Revised Injury Severity Classification (RISC) over Trauma and Injury Severity Score (TRISS) in an independent evaluation of major trauma patients. Journal of International Medical Research. 2010;38:1530-38

8. Guerado E et al : Resuscitation of Polytrauma Patients: The Management of Massive Skeletal Bleeding. The Open Orthopaedics Journal, 2015, 9, (Suppl 1: M3) 283-295 
9. American College Of Surgeons Commitee on Trauma. In: ATLS student course manual. $8^{\text {th }}$ Edition. USA: American College of Surgeons Committee on Trauma; 2008.

10. Solomon L, Warwick D. Apley\& Solomon's Sistem of Orthopaedics and Trauma. Tenth Edition. CRC Press. 2016

11. Salter RB. Textbook of Disorders and Injuries of The Muskuloskeletal System: an Introduction to Orthopaedics, Reumatology, Metabolic Bone Disease, Rehablitation and Fractures. Third Edition. Michigan : William \& Wilkins. 2008

12. Saad S et al. Assessment of the use of TRISS scoring system in polytraumatized patients in Suez Canal university hospital,Ismailia, Egypt. International Surgery Journal. IntSurg J. 2016 Aug;3(3):1524-1527. DOI: http://dx.doi.org/10.18203/2349-2902.isj20162740

13. Joosse, P. An evolution of trauma care evaluation: A thesis on trauma registry and outcome prediction $\bmod (2013)$

14. Champion HR, Sacco WJ, Carnazzo AJ, et al : TRAUMA SCORING. Scandinavian Journal of Surgery 91: $12-22,2002$

15. Jakusonoka R, Jumtins A, et al : The New Injury Severity Score: Availability in E valuation of Severity of Polytrauma Patients with Orthopaedic Injuries. ActaChirurgicaLatviensis. 2009 (9). DOI: 10.2478/v10163-010-0018-1

16. Ranti JSR, Sapan HB, KalesaranLT :Aplikasi revised trauma score, injury severity score, dan trauma and injury severity score dalammemrediksimortalitaspadapasienmultitrauma di IRDB BLU RSUP Prof. Dr. R. D. Kandou Manado. JurnalBiomedik (JBM), Volume 8, Nomor 2 Suplemen, Juli 2016, hlm. S30-S35

17. Domingues $\mathrm{CD}$ et al: New Trauma and Injury Severity Score (TRISS) adjustments for survival prediction. World Journal of Emergency Surgery (2018) 13:12 https://doi.org/10.1186/s13017-0180171-8

18. Iordanis N Papadopoulos, Nikolaos K Kanakaris, Patients with pelvic fractures due to falls:A paradigm that contributed to autopsy-basedA paradigm that contributed to autopsy-basedaudit of trauma in Greeceaudit of trauma in Greec, Journal of Trauma Management \& Outcomes 2011, 5:2

19. Gunawan B et al, Trauma and Injury Severity Score in Predicting Mortality of Polytrauma Patients, Department of Orthopaedic and Traumatology Univercity of Indonesia-Dr. CiptoMangunkusumo Hospital, DOI: 10.23886/ejki.5.8148. Vol. 5, No. 3, December 2017

20. Blackwell TH, Kaufman JS : Response Time Effectiveness: Comparison of Response Time and Survival in an Urban Emergency Medical Services System. Academic Emergency Medicine . April 2002, Volume 9, Number 4

21. Blanchard et al. Ems Response Time In Urban Setting. Prehospital Emergency Care January/March 2012 Volume 16 / Number 1. doi: 10.3109/10903127.2011.614046

22. Mahama $\mathrm{MN}$ et al : Emergency response time and pre-hospital trauma survival rate of the national ambulance service, Greater Accra (January - December 2014. BMC Emergency Medicine (2018) 18:33 https://doi.org/10.1186/s12873-018-0184-3

23. Mayer JD : Response Time and Its Significance in Medical Emergencies. Geographical Review, Vol. 70, No. 1 (January,1980), pp. 79-87. http://www.jstor.org/stable/214369?origin=JSTOR-pdf

24. Wilde et al. Do Emergency Medical System Response Times Matter For Health Outcomes?. Health Econ. 22: 790-806 (2013) DOI: 10.1002/hec

25. S Chowdhury, P H Navsaria, S Edu, A J Nicol, The Effect Of Emergency Medical Services Response On Outcome Of Trauma Laparotomy At A Level 1 Trauma Centre In South Africa, S Afr J Surg 2016;54(4).

26. Sugiono. Metodepenelitiankuantitatifdankualitatif. Bandung : CV alfabeta, 2008.

27. Hirshberg A, Wall MJ Jr, Allen MK, Mattox KL. Double jeopardy: thoracoabdominal injuries requiring surgical intervention in both chest and abdomen. J Trauma. 1995;39:225-31.

28. Kawahara N, Zantut LF, Poggeti RS, Fontes B, Bernini C, Birolini D. Laparascopic treatment of gastric and diaphragmatic injury produced by thoracoabdominal stab wound. J Trauma. 1998;45:613-4.

29. Mefire AC, Pagbe JJ, Fakou M, Nguimbous JF. Analysis of epidemiology, lesions, treatment and outcome of 354 consecutive cases of blunt and penetrating trauma to the chest in an African setting.SAJS. 2010;48:90-3.

30. Morales CH, Villegas MI, Angel W, Va'squezJJ.Value of digital exploration for diagnosing injuries to the left side of diaphragm caused by stab wounds. Arch Surg. 2001;136:1131-5. 
31. Nanda R, Prabisma D, Marshal. Gambaranpenatalaksanaan trauma toraks di RSUP H. Adam Malik Medan. Tesis. DepartemenIlmu Bedah, Fakultas Kedokteran Universitas Sumatera Utara, RSUP H. Adam Malik.; 2015

32. Salim C. SistemPenilaian Trauma, CDK-232/ vol. 42 no. 9, th. 2015 